\title{
Canarium ovatum Engl. (Pili) exocarp crude extract as functional food colorant incorporated in yogurt developed product
}

\author{
${ }^{1 *}$ Aril-dela Cruz, J.V., ${ }^{2}$ Bungihan, M.E., ${ }^{1}$ dela Cruz, T.E.E. and ${ }^{1,3}$ Sagum, R.S. \\ ${ }^{1}$ The Graduate School, University of Santo Tomas, España Manila, 1015, Philippines \\ ${ }^{2}$ Center for the Natural Sciences, St. Mary's University, Bayombong, Nueva Vizcaya, 3700, Philippines \\ ${ }^{3}$ Food and Nutrition Research Institute - Department of Science and Technology
}

\section{Article history:}

Received: 22 August 2017

Received in revised form: 16

September 2017

Accepted: 17 September 2017

Available Online: 28

September 2017

Keywords:

Anthocyanin,

Natural colorant,

Antioxidant,

Yogurt,

Canarium ovatum

DOI:

https://doi.org/10.26656/fr.2017.2(1).173

\section{Abstract}

Canarium ovatum Engl. (Pili), a locally grown plant in the Philippines, bears highly pigmented fruits. In this research study, the deeply pigmented fruit exocarp was evaluated for phytochemical contents, functional properties and possible application to yogurt as a colorant. Spectrophotometric analysis of the extract revealed high phenolic and flavonoid content, particularly anthocyanins $(17.5 \mathrm{mg} \mathrm{CE} / \mathrm{g} \mathrm{DW}$ of the sample). The pigment extract also exhibited potential antioxidant activities as determined by DPPH and FRAP assays and did not show any inhibitory activity against gut normal flora, Escherichia coli, but also failed to express cytotoxic activity against HCT116 colon cancer cell line. Stability tests showed decreased redness with increasing temperature or $\mathrm{pH}$. The pigment exhibited excellent color retention in yogurt during the two-week storage at $4^{\circ} \mathrm{C}$. Sensory evaluation showed a slight difference in over-all acceptability between natural and synthetic-colored yogurt. Thus, Pili exocarp extract can be used as a functional food colorant in yogurt.

\section{Introduction}

Food colorants are added to food to make it more appealing and appetizing. Majority of these colorants are synthetically prepared to pose increased concern on safety. Consequently, consumers are turning to naturallyderived colorants as alternatives. Interestingly, a vast source of colorants may also be derived from natural sources such as plants, animals, and even microorganisms. These sources are considered safe since they are part of the normal human diet. Among the popularly used plant sources are the brightly colored fruits and vegetables, e.g. grapes, blueberries, purple cabbage, red beet, and purple corn (Lakshmi, 2014). Anthocyanins, the chemical responsible for these pigments, have also been tapped as natural colorants for beverages, jellies, candies, and dairy products (Giusti and Wrolstad, 2003). In addition to the color they impart, anthocyanins were also reported to possess antioxidant activity (Wang et al.,1997; Kähkönen and Heinonen, 2003; Zheng and Wang, 2003), anti-inflammatory (Li et al., 2014), anti-tumor and chemoprotective effects (Kamei et al., 1995; Koide et al., 1997; Wang and Stoner, 2008).

Several fruit-bearing trees grown in the Philippines produce highly pigmented fruits likely to be rich in phytonutrients, particularly anthocyanin, and thus, can also be potential sources of natural food dyes. Canarium ovatum Engl., locally known as Pili, is an indigenous tropical nut-producing tree belonging to the family Burseraceae. The trees are erect to spreading, reaching a height of 30 meters or more. The fruit is drupe with an ovoid to ellipsoid shape, 5.0-8.0 centimeters long, and weighing 15.7 to 45.7 grams. It is covered with a thin, smooth and shiny peel or skin called exocarp which turns from green to dark purple color when the fruit is fully ripe. Underneath is a fleshy and fibrous pulp or mesocarp layer. The hard endocarp or shell is elongated and trigonous with the pointed basal end and blunt apical end. It is nearly triangular in transverse section. Inside the shell is the milky kernel with two white cotelydons surrounded by a brown papery seed coat called testa (Coronel, 1996). Almost every part of the Pili tree is utilized either as food, feed, fuel, or handicrafts (Philippines, Department of Agriculture (Phil-DA), 2011), thus locally dubbed as "tree of hope". The tree itself provides good shade for other important crops such as abaca and cacao. From the trunk comes a valued aromatic exudate knew as "Manila elemi" which is becoming popular now in the perfumery and pharmaceutical industry. The young leaves are made into salads. It can also be used in the paper and dye making. 
The fruit pulp when blanched is commonly eaten raw by locals. It is also processed into flour, oil, paste, and other bakery products. The shell is made into handicrafts or used as materials for souvenir items. The nut, the most economically important part of the fruit, is popularly made into confectioneries, candies, and oil (Phil-DA, 2011). However, the brightly pigmented exocarp is usually discarded as waste after the nut and pulp were utilized. Owing to its deep pigmentation, the fruit exocarp is hypothesized to possess phytonutrients with potential functional properties. Thus, this research study aimed to assess the pigment extracts of $C$. ovatum exocarps as a functional food colorant. The results of this study will contribute another application opportunity of the rather regarded waste to the food industry. Also, this may lead to further utilization of the Pili pigment in the pharmaceutical and cosmetic industries as a natural colorant with functional properties.

\section{Materials and methods}

\subsection{Chemicals and reagents}

Ethanol used for extraction was bought from $\mathrm{ACI}$ Labscan (Bangkok, Thailand). Folin-Ciocalteau's phenol reagent, 2,2-diphenyl-1-picrylhydrazyl (DPPH) and 2,4,6 -tri(2pyridyl)-S-triazine (TPTZ) reagents were purchased from Sigma-Aldrich (St. Loius, MO, USA). Standards catechin, ascorbic acid, and vanillin were purchased from Ajax Finechem (New Zealand) and Sigma-Aldrich (St. Loius, MO, USA). Commercially available impregnated discs of ampicillin and tetracycline used as control antibiotics for the antibacterial test were purchased from Oxoid (Thermo Scientific, United Kingdom). Pronadisa chromogenic agars were purchased from Asiagel Corporation, Philippines. All other chemicals and reagents used in the experiments were of analytical grade.

\subsection{Sample preparation and extraction}

Five kg of matured Pili fruits were purchased from a local market in Goa, Camarines Sur, Philippines. The maturity of fruits was determined based on the color of the fruit skin or exocarp which is dark purple to black when fully ripe. Pili fruits without physical damage were carefully selected, washed under running water, and allowed to dry at room temperature. Using a kitchen peeler, exocarps were collected and allowed to air dry for 2-3 days. Sample specimen was submitted to the Botany Section of the National Museum in Manila and was identified as C. ovatum Engl. Approximately 187 grams of dried exocarp were ground using a food blender. Ground samples were placed in a stoppered flask and submerged completely in $500 \mathrm{~mL}$ absolute ethanol for 24 hours. The mixture was then filtered through a Whatman filter paper. Adhering samples on the flask surfaces were collected using fresh portions of ethanol, filtered and combined with the previous filtrate. The mixture was concentrated under vacuum (Eyela evaporator, Japan) at $50^{\circ} \mathrm{C}$ until the ethanol was completely evaporated. Pigment concentration was computed following the protocol of Aguinaldo et al. (2004) and samples were kept in sterile amber vials at refrigerated temperature until further analysis.

\subsection{Determination of the total flavonoid content}

Total flavonoid content was determined using the aluminum chloride colorimetric assay described by Marathakam et al. (2012). Triplicate samples were analyzed and absorbance reading was done at $510 \mathrm{~nm}$ using a spectrophotometer. The total flavonoid content was expressed as mg catechin equivalents (CE)/ g dry weight.

\subsection{Determination of the total phenolic content}

Total phenolic content of the pigment extract was quantified adopting the modified Folin-Ciocalteau colorimetric method described by Chew et al. (2011). Two $\mathrm{mL}$ of diluted pigment extract $(0.5 \mathrm{mg} / \mathrm{ml})$ was mixed with $1 \mathrm{~mL}$ of $1 \mathrm{~N}$ Folin-Ciocalteau reagent and allowed to stand for 5 minutes. The mixture was then added to $4 \mathrm{~mL}$ saturated sodium carbonate solution (60 $\mathrm{g} / \mathrm{L})$. The volume of the mixture was adjusted to $10 \mathrm{~mL}$ by adding distilled water. After 2 hours, the absorbance of the mixture was measured at $760 \mathrm{~nm}$ against a blank. Analysis was done in triplicates. Ascorbic acid solution prepared with different concentrations was used in constructing the standard curve. Results were expressed as mg ascorbic acid equivalent (AAE)/g dry weight of the sample.

\subsection{Determination of the total anthocyanin content}

Total anthocyanin content was determined by a spectrophotometric method using the protocol developed by Fuleki and Francis (1968) with slight modifications. One $\mathrm{ml}$ aliquot of the pigment extract was mixed with $2.5 \mathrm{~mL}$ of $1 \%(\mathrm{w} / \mathrm{v})$ vanillin in ethanol and $2.5 \mathrm{~mL}$ of 9.0 $\mathrm{N}$ hydrochloric acid in ethanol. After 20 mins incubation, samples were read at $520 \mathrm{~nm}$ in a UV-VIS Spectrophotometer (APEL-100, Japan) and the result was expressed as mg catechin equivalent (CE)/gram dry weight sample. Standard calibration was made using catechin solution at different concentrations.

\subsection{Determination of antioxidant activity by DPPH and}


FRAP assay

The DPPH• (2,2-diphenyl-1-picrylhydrazyl) free radical scavenging activity and the ferric-reducing antioxidant power of the pigment extract were used to determine its antioxidant activity following the method described by Yang and Zhai (2010). DPPH assay measures the reduction of DPPH solution in the presence of a hydrogen donating antioxidant. Reduction of the purple color of DPPH to yellow-colored diphenyl-picryl hydrazine signified positive results. Whereas, FRAP assay determines the ability of a sample to reduce ferric to ferrous ion by donating electrons. The percentage reduction of the DPPH free radicals was calculated using the following formula:

DPPH $\cdot$ Free radical scavenging activity $(\%)=$ (Ac - As) x 100/Ac

\section{Where:}

$\mathrm{Ac}=$ absorbance of the control (no sample added)

As $=$ absorbance of the sample

Ascorbic acid was used in constructing the standard calibration curve. Effective Concentration $50 \quad\left(\mathrm{EC}_{50}\right)$ value was calculated to further quantify the concentration of sample required to scavenge $50 \%$ DPPH free radical. On the other hand, FRAP was expressed as mmol $\mathrm{FeSO}_{4}$ equivalents per gram dry weight of the sample. A standard curve was constructed using $\mathrm{FeSO}_{4}$.

\subsection{Test for antibacterial activity}

Antibacterial activity of the pigment extract was evaluated using the paper disc diffusion method described by Ortez (2005). Inocula of approximately $10^{8}$ $\mathrm{CFU} / \mathrm{mL}$ of the standard test bacteria, i.e., Staphylococcus aureus (ATCC 25923), Escherichia coli (ATCC 25922), and Pseudomonas aeruginosa (ATCC 27853), were inoculated onto the sterile surface of Mueller-Hinton agar. Thirty microlilters of the different concentrations, i.e., $1.0,5.0$ and $10.0 \mathrm{mg} / \mathrm{ml}$, of the pigment extract were impregnated into sterile Grade AA Whatman ${ }^{\mathrm{TM}}$ paper discs (6 $\mathrm{mm}$ in diameter) and allowed to dry. Commercially available impregnated antibiotic discs of ampicillin and tetracycline at $10 \mu \mathrm{g} / \mathrm{mg}$ were used as positive controls while the solvent methanol:acetone was used as negative control. After incubation at $35^{\circ} \mathrm{C}$ for 24 hours, the zone of inhibition (ZOI) or the diameter of the clearing zones around each disc was measured in millimeter.
The potential cytotoxicity activity of the pigment extract was tested on human colorectal cancer cell line (HCT 116 cells) using 3-(4,5-dimethylthiazol-2-yl)-2,5diphenyltetrazolium bromide (MTT) assay adapted from the procedure of Mosmann (1983). The Inhibition Concentration $50 \quad\left(\mathrm{IC}_{50}\right)$ was computed using the software "icpin" which uses a linear interpolation of the graph of absorbance against concentration. Doxorubicin served as positive control while DMSO served as negative control.

\subsection{Stability testing of the pigment extract at different $\mathrm{pH}$ and temperature}

\subsubsection{Temperature}

Four test samples were prepared by dissolving the pigment extract $(0.04 \mathrm{~g})$ in distilled water $(40 \mathrm{ml})$. The test samples were then incubated for 30 minutes at different temperatures mimicking processing and storage conditions: at $4^{\circ} \mathrm{C}$ (refrigerated), $25^{\circ} \mathrm{C}$ (ambient), $75^{\circ} \mathrm{C}$ (pasteurization), and $100^{\circ} \mathrm{C}$ (boiling/cooking). Spectral characteristics were determined. Each treatment was shot three times using a chromameter (Konica Minolta Chromameter CR400, Japan) calibrated against a white plate. The values obtained were used to assess the color differences between the treatments relative to $4^{\circ} \mathrm{C}$ using the formula (adapted from Cai and Corke, 1999):

$$
\Delta \mathrm{E}^{*}=\left[\left(\Delta \mathrm{L}^{*}\right)^{2}+\left(\Delta \mathrm{a}^{*}\right)^{2}+\left(\Delta \mathrm{b}^{*}\right)^{2}\right]^{1 / 2}
$$

Hue angle was also calculated following the formula (adapted from McLellan et al., 1994):

$$
\text { Hue angle }\left(\mathrm{H}^{\circ}\right)=\tan ^{-1}\left(\frac{b *}{a *}\right)
$$

Hue angle quantitatively indicates color shift such that $0^{\circ}$ or $360^{\circ}$ denoted red hues, $90^{\circ}$ for yellow, $180^{\circ}$ for green, and $270^{\circ}$ for blue.

\section{9. $2 \mathrm{pH}$}

Approximately $0.04 \mathrm{~g}$ of the extract was dissolved in buffer solution $(40 \mathrm{ml})$ with different $\mathrm{pH}$ values, i.e., $\mathrm{pH}$ 4, pH 7 and pH10, and allowed to stand for 30 minutes. Munsell color and the spectral characteristics of the pigment extract was measured using the same chromameter. Results were expressed as L* (lightness), $a^{*}$ (+red/-green), and b* (+yellow/-blue). Each treatment was shot three times. Color differences relative to $\mathrm{pH} 4$ and hue angle were also calculated.

\subsection{Application of pigment extract as natural colorant to yogurt}




\subsubsection{Preparation of yogurt with Pili exocarp colorant}

Natural colorant for the yogurt was prepared by mixing $2 \mathrm{~g}$ of the pigment extract with $20 \mathrm{ml}$ honey. Honey was used as a carrier for the colorant and as a sweetener for the yogurt. The mixture was stirred gently until completely mixed. The Pili exocarp colorant was then added to $1,000 \mathrm{ml}$ of full cream milk prior to pasteurization at $70-75^{\circ} \mathrm{C}$ for 30 minutes. Probiotic starter $(0.06 \% \quad \mathrm{w} / \mathrm{w})$ containing mix cultures of Lactobacillus delbrueckii subsp. bulgaricus and Streptococcus salivarius subsp. thermophilus was added when the mixture had cooled down to $45^{\circ} \mathrm{C}$. This was further incubated at $40-45^{\circ} \mathrm{C}$ for about $7-10$ hours until the $\mathrm{pH}$ drops to 4.5-4.6. Two other yogurts with and without artificial pigment served as controls.

\subsubsection{Determination of color characteristics and retention}

The color characteristics of the three prepared yogurt samples were measured using a chromameter (Konica Minolta Chromameter CR400, Japan) calibrated against a white plate. Results were expressed as L*(lightness), $a^{*}(+$ red/-green $)$, and $b^{*}(+$ yellow/-blue $)$. From these values, chroma (C) or color intensity/saturation was computed using this formula (adapted from Cai and Corke, 1999):

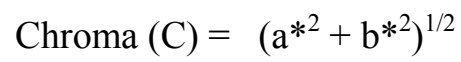

Where in high $\mathrm{C}$ value denoted more intense color.

To determine color retention of the Pili exocarp colorant in yogurt, small vials containing $50 \mathrm{~g}$ of the yogurt were stored over a two-week period at refrigerated $\left(4^{\circ} \mathrm{C}\right)$ temperature. Color characteristics and $\mathrm{pH}$ were measured at day 0,7 and 14 using the same chromameter and a $\mathrm{pH}$ meter, respectively. Duplicate samples were used for this purpose. Munsell color was also determined using the same chromameter. Percent color retention $(\% \mathrm{CR})$ was also calculated using the formula:

Color retention $(\%)=\mathrm{C}$ value at $\mathrm{Z}$ storage time $\mathrm{X} \frac{10^{2}}{\mathrm{C} \text { value at } O \text { storage time }}$

Color differences of the treatments relative to the initial reading at week 0 were computed using equation 2. Color shifts were also determined by computing the hue angle following equation 3 .

\subsection{Microbiological analysis}

Microbiological analysis of the yogurt sample with the developed natural colorant was performed with slight modifications of the methods stipulated in the Bacteriological Analytical Manual (United States Food and Drug Administration (US FDA), 2001). Freshly prepared yogurt with Pili exocarp colorant was tested for Coliform, Escherichia coli, Salmonella, and Coagulase (+) Staphylococcus aureus as specified for yogurt and other fermented milk in the "Revised guidelines for the assessment of microbiological quality of processed food" (Department of Health- Food and Drug Administration (DOH-FDA), 2013). $\quad$ Pronadisa $^{\circledR}$ Salmonella chromogenic agar, E. coli-Coliform chromogenic agar, and Baird-Parker Agar with Egg yolk suspension (S. aureus) were used for the analyses. Lactic acid bacteria were also quantified using de Man, Rogosa and Sharpe (MRS) agar. Twenty-five (25) grams of yogurt sample was mixed with $225 \mathrm{ml} 0.1 \%$ peptone water producing a $10^{-1}$ dilution. Serial dilution was performed until $10^{-4}$. After which, $0.1 \mathrm{ml}$ aliquot was obtained from each dilution as well as from the undiluted yogurt sample and inoculated onto solidified sterile agar plates mentioned above. The inoculum was spread using a sterile, bent glass rod and allowed to dry for about 5 minutes. All culture plates (in duplicates) were then incubated at $37^{\circ} \mathrm{C}$ for 24 hours. Following incubation, colonies of coliform (salmon to red colonies on E. coliColiform chromogenic agar), E. coli (dark blue to violet colonies on E. coli-Coliform chromogenic agar), Salmonella (magenta colonies on Salmonella chromogenic agar), and $S$. aureus (black colonies on Baird-Parker Agar with Egg yolk suspension) were counted. If positive for the target bacteria, colony forming unit per gram sample was computed using the following equation:

$$
\frac{C F U}{g}=\frac{\text { average of colonies counted }}{\text { volume of inoculumused }} X \text { dilution factor }
$$

where dilution factor is the reciprocal of the dilution used.

However, if results are negative, only no growth was reported in the results indicating the absence of the target bacteria from the prepared yogurt.

The lactic acid bacteria in the prepared yogurt were also quantified on de Man, Rogosa and Sharpe (MRS) agar using pour plate method. Sterile, molten paraffin was poured over the solidified agar surface forming an overlay in order to create an anaerobic condition that will facilitate the growth of the facultative anaerobic lactic acid bacteria. The culture plates were then incubated at $37^{\circ} \mathrm{C}$ for 48 hours. After incubation, colonies were counted manually and $\mathrm{CFU} / \mathrm{g}$ was calculated using equation 6 . 


\subsection{Sensory acceptability of the developed yogurt}

Consumer acceptability test of the yogurt samples was conducted through sensory evaluation. Fifty (50) untrained panelists were asked to assess the sensory attributes of the prepared yogurts (i.e., yogurt with Pili exocarp colorant, yogurt with artificial colorant, and yogurt without colorant). The appearance, color, aroma, taste, mouth-feel, and overall acceptability of the samples were evaluated using a 7-point hedonic consumer preference test.

\subsection{Statistical analysis}

Data analysis and statistical computation for the analysis of variance (ANOVA) and Duncan's Multiple Range Test were performed using SigmaStat version 3.1. Significant difference was defined at $\rho<0.05$.

\section{Results and discussion}

\subsection{Phytochemical content and antioxidant properties of} the Pili pigment extract

A thick semi-solid, dark purple paste was extracted from the dried Pili exocarp. Total flavonoid, phenolic, anthocyanin content and antioxidant activities are presented in Table 1. The results support the hypothesis that the Pili exocarp being highly pigmented is rich in anthocyanin. Phenolic compounds such as anthocyanins are known natural antioxidant (Wang and Mazza, 2002; Kahkonen and Heinonen, 2003; Gnanavinthan, 2013). As revealed by the Effective Concentration $\left(\mathrm{EC}_{50}\right)$ value, a very small amount $(0.0071 \mathrm{mg} / \mathrm{ml})$ of the extract is required to reduce the amount of the radical DPPH in the solution to $50 \%$. These phytochemicals may, therefore, be responsible for the significant radical scavenging activity and ferric reducing ability of the extract, indicating a promising antioxidant potential. Consistent with these results, Chew et al. (2011) reported comparable radical scavenging activity of the whole edible portion (pulp and skin) of Canarium odontophyllum, a botanical relative of $C$. ovatum.

\subsection{Antibacterial and cytotoxic activities of the Pili pigment extract}

In this study, the pigment crude extract from the Pili exocarp failed to inhibit the test bacteria Staphylococcus aureus ATCC 25923, Escherichia coli ATCC 25922, and Pseudomonas aeruginosa ATCC 27853 as shown by the absence of zone of inhibition in the disc diffusion assay. The results can be interpreted from two perspectives. First, this simply showed that the Pili pigment did not exhibit any inhibitory activity against the test bacteria, and hence, its phytochemical constituents do not have any antibacterial property. Secondly, on the other hand, the absence of inhibitory activity could also suggest a lesser toxicity against human gut flora as exemplified by the absence of inhibition against Escherichia coli, a known normal bacterial gut flora. Since it is the goal of the research to incorporate this pigment in yogurt which is consumed orally, the developed product should not have any antagonistic effect against beneficial microorganisms found in our colon. In addition, this also showed that the pigment extract may not exhibit inhibitory activity against probiotic microorganisms, the gram-positive bacteria Lactobacillus and Streptococcus, present in yogurt since it also failed to inhibit the gram-positive test bacteria, Staphylococcus aureus. This is further supported by the growth of lactobacilli in the developed yogurt presented below.

Similarly, MTT assay showed little or no cell death against the human colorectal cancer cell line HCT 116 indicating that the Pili pigment did not cause any cytotoxic activity even at the highest concentration tested, i.e., $50 \mu \mathrm{g} / \mathrm{ml}$. The National Cancer Institute in the US limits the activity of crude extract at $50 \%$ inhibition $\left(\mathrm{IC}_{50}\right)$ after 72 hours of exposure to less than $30 \mu \mathrm{g} / \mathrm{ml}$ or below to be considered cytotoxic (Vijayarathna and Sasidharan, 2012). This inactivity against the test microbes and cancer cell lines could perhaps be attributed to the use of crude Pili extract where flavonoids exist in glycosidic form. Although this was not tested in this study, the glycosidic form of the flavonoids contained sugar molecules that decreased the effectiveness of the compound against some bacteria as mentioned by Rhee et al. (1994), Kapoor et al. (2007) and Parvathy et al. (2009). Likewise, in previous reports on cytotoxic activities of anthocyanin (Malik et al., 2003; Zhang et al., 2005), purified anthocyanidins, the aglycone of anthocyanin were used. The free hydroxyl group in 3 position of anthocyanidin may have contributed to their anti-proliferative activity of the compound. In the case of anthocyanin, activity was

Table 1. Total flavonoid, phenolic, anthocyanin contents and antioxidant activities of the Pili crude pigment extract.

\begin{tabular}{cccccc}
\hline $\begin{array}{c}\text { Total flavonoid } \\
(\mathrm{mg} \mathrm{CE} / \mathrm{g} \mathrm{DW})^{1}\end{array}$ & $\begin{array}{c}\text { Total phenolic } \\
(\mathrm{mg} \mathrm{AAE} / \mathrm{g} \\
\mathrm{DW})^{2}\end{array}$ & $\begin{array}{c}\text { Total } \\
\text { anthocyanin } \\
(\mathrm{mg} \mathrm{CE} / \mathrm{g} \mathrm{DW})\end{array}$ & $\begin{array}{c}\text { DPPH } \\
(\% \mathrm{RSA} \text { at } \\
1 \mathrm{mg} / \mathrm{ml})^{3}\end{array}$ & $\begin{array}{c}\mathrm{EC}_{50} / \mathrm{DPPH} \\
(\mathrm{mg} / \mathrm{ml})\end{array}$ & $\begin{array}{c}\text { FRAP } \\
(\mathrm{mmolFeSO} / \\
\mathrm{g} \mathrm{DW})\end{array}$ \\
\hline 2.2 & 8.8 & 17.5 & 82.1 & 0.0071 & 32.0 \\
\hline
\end{tabular}


prevented by the substitution of the hydroxyl group by different sugar moieties.

\subsection{Pigment stability of the Pili pigment extract}

Colorimetric analysis using Konica Minolta Chromameter CR400 characterized the Pili pigment as red. When subjected to different temperatures, the redness was more pronounced at a lower temperature $\left(4^{\circ} \mathrm{C}\right)$ and a significant reduction in redness $\left(a^{*}\right)$ was noted when the temperature was elevated (Figure 1). A similar effect was reported by Hou et al. (2013) on the anthocyanins isolated from black rice. Furthermore, color shifted from red to yellow-red when exposed to higher temperatures $\left(70-100^{\circ} \mathrm{C}\right)$ as elucidated by the increase in hue angle values (Table 2). Computed value for color difference $\left(\Delta \mathrm{E}^{*}\right)$ relative to $4^{\circ} \mathrm{C}$ decreased as the temperature is increased. These results suggest that high temperature accelerated the degradation of anthocyanin resulting in color change. Hence, these indicate better color stability of the pigment at refrigerated temperature. In the same manner, $\mathrm{pH}$ also affected the color characteristic and stability (Table 2). Redness was again more pronounced at lower $\mathrm{pH}$, i.e., $\mathrm{pH} 4$ (Figure 1). At neutral (7) to higher (10) $\mathrm{pH}$, this redness substantially decreased and resulted in the shift of the color from red to yellow-red. Similarly, in the study of Assous et al. (2014), the stability of the anthocyanin extracted from purple carrots was also observed at acidic $\mathrm{pH}$ (1-5) while rapid degradation occurred at $\mathrm{pH} 7$.
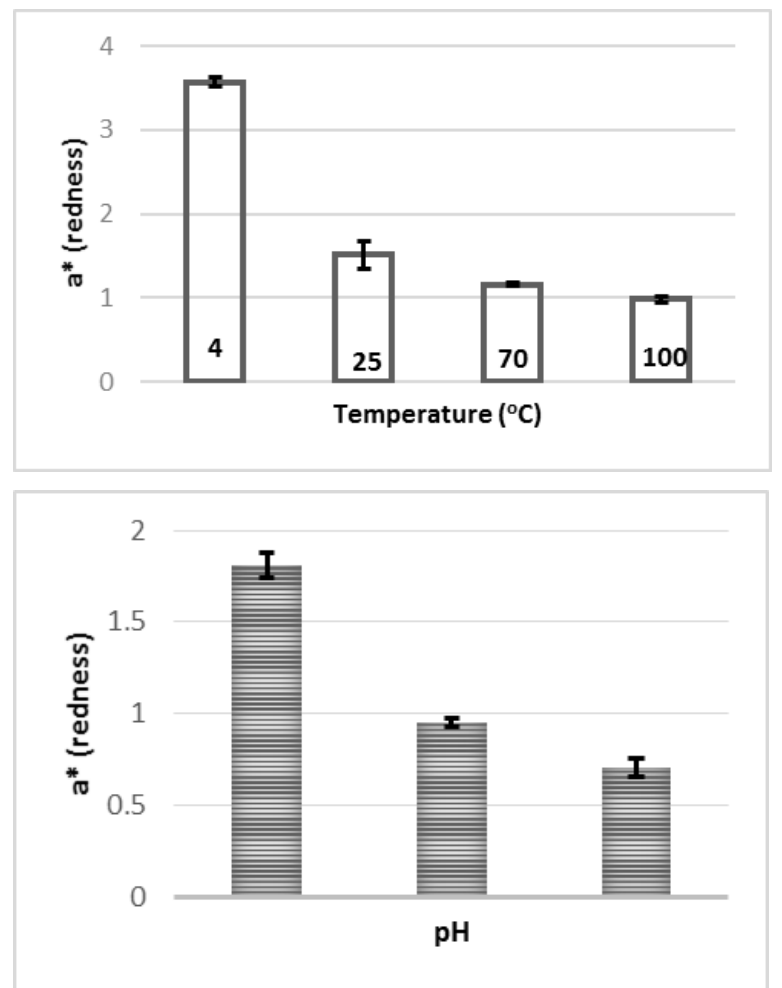

Figure 1. Effect of temperature (A) and $\mathrm{pH}(\mathrm{B})$ on redness of the Pili pigment extract.
3.4 Color characteristics and retention of Pili pigment extract

The Pili pigment extract which was found to be rich in anthocyanin imparted a uniform purplish color to the developed yogurt similar to a commercial blueberry yogurt. However, previous studies showed that naturallyderived colorants normally fade over time (Cai and Corke, 1999; Krammerer et al., 2006; Wallace and Giusti, 2008). It is therefore vital to maintain the stability of the developed product amidst varying processing and storage conditions. In this study, the redness was more pronounced in yogurt with artificial colorant than yogurt with Pili exocarp colorant as shown in the a* values (Table 3). This is further supported by the higher or more intense/saturated color given by the $\mathrm{C}$ value. The developed yogurt with the natural colorant was also monitored in terms of $\mathrm{pH}$ and color characteristics for two weeks at refrigerated temperature $\left(4^{\circ} \mathrm{C}\right)$. As shown in Table 4, the yogurt sample retained its redness based on the Munsell color over the two-week storage. Looking at the $\mathrm{a}^{*}$ values, the redness was even enhanced with prolonged storage up to two weeks. Perhaps, this can be attributed to the lowering of $\mathrm{pH}$. At a lower $\mathrm{pH}$, anthocyanins were primarily present in the form of red flavylium cations (Wang et al., 2013). Interestingly, there was an excellent color retention of the Pili pigment in the developed yogurt (Table 4). This was substantiated by the increase in color saturation as shown in the $\mathrm{C}$ value and \% Color Retention obtained within the two weeks of storage. Similar results were obtained in the study on the retention of Berberis boliviana anthocyanin applied in yogurt (Wallace and Giusti, 2008) and yogurt supplemented with natural betacyanin extract from Opuntia soehrensii seeds stored at $4^{\circ} \mathrm{C}$ for four weeks (Caldas-Cueva et al., 2016). This could be again due to the lowering of the $\mathrm{pH}$ of yogurt. During the fermentation process in yogurt, the probiotic bacteria, Lactobacillus delbrueckii subsp. bulgaricus and Streptococcus salivarius subsp. thermophilus, produced lactic acid resulting in the decrease in $\mathrm{pH}$ of yogurt. This was also evident on the yogurt prepared by Bashiti (2010) using native starters isolated from locally made yogurts. Interestingly, in the study of Arslan and Bayrakci (2016), phenolic contents and antioxidant activity of persimmon-supplemented yogurt were enhanced after two weeks of storage. Phenolic stability was also observed in yogurt containing Berberis boliviana anthocyanin over an eight-week refrigerated storage (Wallace and Giusti, 2008). These prove that the functional colorant from fruit and vegetable pigments would certainly add value to healthy products such as yogurt. 
Table 2. Effect of temperature and $\mathrm{pH}$ on the color stability of Pili pigment extract ${ }^{1}$.

\begin{tabular}{cccccccc}
\hline $\begin{array}{c}\text { Temperature } \\
\left({ }^{\circ} \mathrm{C}\right)\end{array}$ & $\begin{array}{c}\text { Exposure time } \\
\text { (mins) }\end{array}$ & $\mathrm{L}^{*^{2}}$ & $\mathrm{a}^{*^{2}}$ & $\mathrm{~b}^{*^{2}}$ & $\Delta \mathrm{E}^{*^{3}}$ & $\begin{array}{c}\text { Hue Angle } \\
\left(\mathrm{H}^{\mathrm{o}}\right)\end{array}$ & $\begin{array}{c}\text { Hue } \\
\text { (Munsell) }\end{array}$ \\
\hline 4 & 30 & $22.42+0.24^{\mathrm{a}}$ & $3.57+0.05^{\mathrm{a}}$ & $2.50+0.08^{\mathrm{a}}$ & - & 35.00 & Red \\
25 & 30 & $19.45+2.04^{\mathrm{b}}$ & $1.51+0.17^{\mathrm{b}}$ & $1.19+0.04^{\mathrm{b}}$ & 3.84 & 38.24 & Red \\
70 & 30 & $21.27+0.17^{\mathrm{ab}}$ & $1.16+0.01^{\mathrm{c}}$ & $0.96+0.04^{\mathrm{c}}$ & 3.08 & 39.61 & Yellow-Red \\
100 & 30 & $21.48+0.10^{\mathrm{ab}}$ & $0.98+0.04^{\mathrm{d}}$ & $1.18+0.05^{\mathrm{b}}$ & 3.05 & 50.29 & Yellow-Red \\
\hline $\mathrm{pH}$ & $\begin{array}{c}\text { Exposure time } \\
\text { (mins) }\end{array}$ & $\mathrm{L}^{*}$ & $\mathrm{a}^{*}$ & $\mathrm{~b}^{*}$ & $\Delta \mathrm{E}^{*}$ & $\mathrm{H}^{\mathrm{o}}$ & $\begin{array}{c}\text { Hue } \\
\text { (Munsell) }\end{array}$ \\
\hline 4 & 30 & $22.07+0.24^{\mathrm{a}}$ & $1.81+0.07^{\mathrm{a}}$ & $0.83+0.04^{\mathrm{a}}$ & - & 24.63 & Red \\
7 & 30 & $20.56+0.12^{\mathrm{a}}$ & $0.95+0.02^{\mathrm{b}}$ & $1.04+0.03^{\mathrm{b}}$ & 1.75 & 47.59 & Yellow-Red \\
10 & 30 & $21.18+0.01^{\mathrm{a}}$ & $0.70+0.05^{\mathrm{c}}$ & $1.16+0.00^{\mathrm{c}}$ & 1.46 & 58.89 & Yellow-Red \\
\hline
\end{tabular}

${ }^{1}$ Statistical analysis: a-d means different letters within the same column differs significantly $(\mathrm{p}<0.05)$

${ }^{2}$ Color dimensions: $\mathrm{L}^{*}=0$ (black); $\mathrm{L}^{*}=100$ (diffused white); $\mathrm{a}^{*}=$ red; $-\mathrm{a}^{*}=$ green; $+\mathrm{b}^{*}=$ yellow; $-\mathrm{b}^{*}=\mathrm{blue}$

${ }^{3} \Delta \mathrm{E}^{*}$ calculated relative to $4^{\circ} \mathrm{C}$ and $\mathrm{pH} 4$

Table 3. Color comparison of the prepared yogurt samples ${ }^{1}$.

\begin{tabular}{lcccc}
\hline Yogurt sample & $\mathrm{L}^{* 2}$ & $\mathrm{a}^{*^{2}}$ & $\mathrm{~b}^{*^{2}}$ & Chroma \\
\hline Yogurt with artificial red colorant & $73.55+0.01^{\mathrm{a}}$ & $17.01+0.01^{\mathrm{a}}$ & $10.40+0.04^{\mathrm{a}}$ & 19.94 \\
Yogurt with Pili exocarp colorant & $57.04+0.06^{\mathrm{b}}$ & $9.20+0.05^{\mathrm{b}}$ & $6.20+0.13^{\mathrm{b}}$ & 11.09 \\
Yogurt without colorant & $83.27+0.22^{\mathrm{c}}$ & $-0.88+0.01^{\mathrm{c}}$ & $12.41+0.09^{\mathrm{c}}$ & 12.44 \\
\hline
\end{tabular}

${ }^{1}$ Statistical analysis: a-c means different letters within the same column differs significantly $(\mathrm{p}<0.05)$

${ }^{2}$ Color dimensions: $\mathrm{L}^{*}=0$ (black); $\mathrm{L}^{*}=100$ (diffused white); $\mathrm{a}^{*}=\mathrm{red} ;-\mathrm{a}^{*}=$ green; $+\mathrm{b}^{*}=$ yellow; $-\mathrm{b}^{*}=\mathrm{blue}$

Table 4. Color retention of yogurt with Pili exocarp colorant in a two-week storage period ${ }^{1}$.

\begin{tabular}{cccccccccc}
\hline Week & $\mathrm{pH}$ & $\mathrm{L}^{* 2}$ & $\mathrm{a}^{*^{2}}$ & $\mathrm{~b}^{* 2}$ & Chroma & $\begin{array}{c}\Delta \mathrm{E}^{*} \\
3\end{array}$ & $\begin{array}{c}\text { Hue Angle } \\
\left(\mathrm{H}^{\circ}\right)\end{array}$ & $\begin{array}{c}\text { Color retention } \\
(\%)\end{array}$ & $\begin{array}{c}\text { Hue } \\
(\text { Munsell })\end{array}$ \\
\hline 0 & 4.6 & $57.04+0.06^{\mathrm{a}}$ & $9.20+0.05^{\mathrm{a}}$ & $6.20+0.13^{\mathrm{a}}$ & 11.09 & - & 33.98 & - & Red \\
1 & 4.4 & $62.66+0.60^{\mathrm{b}}$ & $10.09+0.06^{\mathrm{b}}$ & $4.35+0.17^{\mathrm{b}}$ & 10.98 & 5.98 & 23.32 & 99.04 & Red \\
2 & 4.3 & $64.93+0.00^{\mathrm{c}}$ & $11.05+0.00^{\mathrm{c}}$ & $4.17+0.00^{\mathrm{bc}}$ & 11.81 & 8.35 & 20.68 & 107.49 & Red \\
\hline
\end{tabular}

${ }^{1}$ Statistical analysis: a-c means different letters within the same column differs significantly $(\rho<0.05)$

${ }^{2}$ Color dimensions: $\mathrm{L}^{*}=0$ (black); $\mathrm{L}^{*}=100$ (diffused white); $\mathrm{a}^{*}=$ red; $-\mathrm{a}^{*}=$ green; $+\mathrm{b}^{*}=$ yellow; $-\mathrm{b}^{*}=\mathrm{blue}$

${ }^{3} \Delta \mathrm{E}^{*}$ calculated relative to $4^{\circ} \mathrm{C}$ and $\mathrm{pH} 4$

\subsection{Microbiological and sensory acceptability of the prepared yogurt with natural colorant}

To ensure that the developed yogurt with natural colorant is safe for consumption, microbiological analyses were conducted. Coliforms including E.coli and other pathogenic organisms (Salmonella, S. aureus) were not detected as shown by the absence of growth on the chromogenic culture agar. On the other hand, lactic acid bacteria were quantified to be $2.5 \times 10^{6} \mathrm{CFU} / \mathrm{g}$. This count passed the required number of viable lactic acid bacteria in yogurt (DOH-FDA, 2013). The value of yogurt as a probiotic product is due to the presence of these live microorganisms. These probiotic microorganisms such as lactic acid bacteria provide health benefits which includes but not limited to the control of intestinal infections, reduction of lactose intolerance, reduction of serum cholesterol levels, and anticarcinogenic activities as mentioned by Lourens-
Hattingh and Viljoen (2001), Adolfsson et al. (2004) and Kechagia et al. (2013). Hence, any additives to yogurt, e.g. colorants, flavorings, or fruits, should not interfere with or inhibit the growth of probiotic bacteria.

The successful application as the natural colorant of the extracted pigment from Pili exocarp produced a uniform purplish-pink color in yogurt. Analysis of variance of the consumer acceptability test showed no significant difference between the yogurt incorporated with Pili exocarp pigment and with a commercial red food colorant when it comes to appearance, aroma, and taste. However, there is a significant difference between color and mouth-feel. For color, yogurt with artificial colorant was preferred over the other two yogurt samples due to the bright color appearance made by the artificial colorant, making the product more attractive. However, for the mouth-feel (i.e., consistency), the respondents preferred yogurt without any colorant. Comparing the 
different criteria, taste obtained the lowest scores among the sensory parameters. Based also on written comments and feedbacks, most evaluators preferred yogurt to be sweeter. Highest values were given to color and appearance for both yogurt with artificial and natural colorant. This simply showed that consumers often rely on visual characteristics of food products for preference with inclination to colored foods. Consistent with these results, Garber et al. (2000) and Griffiths (2005) noted that color of the food or beverages also affects flavor perception. In addition, appetites were also stimulated by color (Lakshmi, 2014). Looking at the overall acceptability, respondents still preferred yogurt with artificial colorant followed by yogurt without colorant and the least was yogurt with Pili exocarp pigment. Interestingly, in spite of their preference for yogurt with artificial colorant, all the yogurt samples received grades between 5 (like slightly) and 6 (like moderately). This showed that generally the respondents slightly or moderately like the prepared yogurt. Although not performed in this study, prolonged storage may result in rheological and physical changes. These may lead to a reduction in sensory characteristics and consequently, decreased probability of consumer acceptability. Previous studies showed that titratable acidity, computed as \% lactic acid, significantly increased due to the continued metabolic activity of the lactic acid bacteria (Serra et al., 2009; Izadi et al., 2015; Arslan and Bayrakci, 2016). In the study of Izadi et al. (2015), the initial increase in firmness, apparent viscosity, and syneresis or the leaking of liquid from the gel due to the separation of whey were observed but this eventually decreased over time.

\section{Conclusion}

This research studied the potential application of pigment obtained from the exocarp of Pili (Canarium ovatum Engl) as a functional colorant to yogurt. The thick, semi-solid, dark purple paste extracted from the exocarp was found to possess antioxidant activity that could be attributed to the phytonutrients present particularly anthocyanin. The pigment extract was successfully incorporated in yogurt as a functional ingredient. The pigment extract was comparable with commercial colorant when applied to yogurt in terms of color and appearance. Furthermore, it presented excellent color retention over the two-week storage at refrigerated temperature $\left(4^{\circ} \mathrm{C}\right)$, hence, a potential alternative for the synthetic colorant. This study is the first to investigate the property and use of the Pili exocarp which is normally discarded as agricultural waste, thus results generated from this research endeavor may open opportunities for application for this valued crop.

Further isolation and quantification of the pigment extracted from the fruit exocarp using High Performance Liquid Chromatography are recommended to better elucidate its phytochemical profiles. It is also suggested that further purification and fractionation of the crude extract be done to isolate the bioactive compounds particularly anthocyanin and test these compounds against other cancer cell lines. Further studies may also be done on varying concentrations of the pigment extract to obtain the most appealing color without compromising the taste and quality of the product.

\section{Conflict of Interest}

The authors declare that there was no conflict of interest in the conduct of this study.

\section{Acknowledgements}

This research work was supported by the Department of Science and Technology- Science Education Institute (DOST-SEI) through the National Science Consortium Graduate Scholarship Program. The authors wish to thank the Research Center for Natural and Applied Sciences of the University of Santo Tomas, Department of Science and Technology- Food Nutrition Research Institute, Mammalian Cell Culture Laboratory of the University of the Philippines and St. Mary's UniversityCenter for Natural Sciences for the facilities made available during the conduct of this study. Lastly, to the Dairy Research and Training Institute of the University of the Philippines - Los Baños and UST Collection of Microbial Strains for the microbial cultures provided.

\section{References}

Adolfsson, O., Meydani, S.N. and Russell, R.M. (2004). Yogurt and gut function.

The American Journal of Clinical Nutrition, 80, 245256.

Aguinaldo, A.M., Espeso, E.J., Guevara, B.Q. and Nonato, M.G. (2004). Phytochemistry Section. In Guevara, B.Q. (Ed.), A Guidebook to Plant Screening: Phytochemical and Biological, p. 24-25. Philippines: Research Center for the Natural Sciences.

Arslan, S. and Bayrakci, S. (2016). Physicochemical, functional and sensory properties of yogurts containing persimmon. Turkish Journal of 
Agriculture and Forestry, 40, 68-74.

Assous, M.T.M., Abdel-Hady, M.M. and Medany, G.M. (2014). Evaluation of red pigment extracted from purple carrots and its utilization as antioxidant and natural food colorants. Annals of Agricultural Science, 59(1), 1-7.

Bashiti, T. (2010). Production of yogurt by locally isolated starters: Streptococcus thermophiles and Lactobacillus bulgaricus. Journal of Al-azhar University- Gaza (ICBAS Special Issue), 12, 56-58.

Cai, Y. and Corke, H. (1999). Amaranthus betacyanin pigments applied in model food systems. Journal of Food Science: Food Chemistry and Toxicology, 64 (5), 869-873.

Caldas-Cueva, J.P., Morales, P., Ludeña, F., BetalleluzPallardel, I., Chirinos, R., Noratto, G. and Campo, D. (2016). Stability of betacyanin pigments and antioxidants in Ayrampo (Opuntia soehrensii Briton and Rose) seed extracts and as a yogurt natural colorant. Journal of Food Processing and Preservation, 40(3), 541-549

Chew, L.Y., Prasad, K. N., Amin, I., Azrina, A. and Lau, C.Y. (2011). Nutritional composition and antioxidant properties of Canarium odontophyllum Miq. (dabai) fruits. Journal of Food Composition and Analysis, 24, 670-677.

Coronel, R.E. (1996). Pili nut. Canarium ovatum Engl. Promoting the conservation and use of underutilized and neglected crops. 6. Rome, Italy: Institute of Plant Genetics and Crop Plant Research, Gatersleben/International Plant Genetic Resources Institute.

Department of Health- Food and Drug Administration (DOH-FDA). (2013). Revised Guideline for the Assessment of Microbiological Quality of Processed Foods. Bureau circular no. 010, series 2013. Philippines: Department of Health - Food and Drug Administration.

Fuleki, T. and Francis, F.J. (1968). Quantitative methods for anthocyanins. Journal of Food Science, 33(1), 71 -77 .

Garber, L., Hyatt, E.M. and Starr Jr., R.G (2000). The effects of food color on perceived flavor. Journal of Marketing: Theory and Practice, 59-71.

Giusti, M.M. and Wrolstad, R.E. (2003). Acylated anthocyanins from edible sources and their applications in food systems. Biochemical Engineering Journal, 14, 217-225.

Gnanavinthan, A. (2013). Introduction to the Major Classes of Bioactives Present in Fruit. In Skinner,
M. and Hunter, D. (Eds.), Bioactives in Fruit: Health Benefits and Functional Foods, p. 1-15. New York: John Wiley and Sons, Ltd.

Griffiths, J. (2005). Coloring Foods and Beverages. Food Technology, 59(5), 38-44.

Hou, Z., Qin, P., Zhang, Y., Cui, S. and Ren, G. (2013). Identification of anthocyanins isolated from black rice (Oryza sativa L.) and their degradation kinetics. Food Research International, 50, 691-697.

Izadi, Z., Nasirpour, A., Garoosi, G.A. and Tamjidi, F. (2015). Rheological and physical properties of yogurt enriched with phytosterol during storage. Journal of Food Science and Technology, 52(8), 5341-5346.

Kähkönen, M. and Heinonen, M. (2003). Antioxidant activity of anthocyanins and their aglycons. Journal of Agricultural and Food Chemistry, 51, 628-633.

Kamei, H., Kojima, T., Hasegawa, M., Koide, T., Umeda T., Yukawa, T. and Terabe, K. (1995). Suppression of tumor cell growth by anthocyanins in vitro. Cancer Investigation, 13(6), 590-594.

Kapoor, N., Narain, U. and Misra, K. (2007). Bioactive conjugate of curcumin having ester peptide, thiol and disulphide links. Journal of Scientific and Industrial Research, 66, 647-650.

Kechagia, M., Basoulis, D., Konstantopoulou, S., Dimitriadi,D., Gyftopoulou,K., Skarmoutsou, N. and Fakiri, E.M. (2013). Health benefits of probiotics: A review. ISRN Nutrition, 1-7. http:// dx.doi.org/10.5402/2013/481651

Koide, T., Kamei, H., Hashimoto, Y., Kojima, T. and Hasegawa, W. (1997). Antitumor effect of anthocyanin fractions extracted from red soybeans and red beans in vitro and in vivo. Cancer Biotherapy and Radiopharmacology, 12(4), 277280.

Krammerer, D., Schillmoller S., Maier, O., Schieber A. and Reinhold, C. (2006). Colour stability of canned strawberries using black carrot and elderberry juice concentrate as natural colorants. European Food Research Technology, 224, 667-669.

Lakshmi, C.G. (2014). Food Coloring: The Natural Way. Research Journal of Chemical Sciences 4(2), 87-96.

Li, H., Deng, Z., Liu R., Loewen, S. and Tsao, R. (2014). Bioaccessibility, in vitro antioxidant activities and in vivo anti-inflammatory activities of a purple tomato (Solanum lycopersicum L.). Food Chemistry, 159, 353-360.

Lourens-Hattingh, A. and Viljoen, B. (2001). Yogurt as probiotic carrier food. International Dairy Journal, 
$11,1-17$.

Malik, M., Zhao, C., Schoene, N., Guisti, M., Moyer, M. and Magnuson, B. (2003). Anthocyanin-rich extract from Aronia meloncarpa induces a cell cycle block in colon cancer but not normal colonic cells. Nutrition and Cancer, 46(2), 186-196.

Marathakam, A., Kannappan, N., Jasemine S., Santhiagu, A., Sreejith, M. and Ajith M.P. (2012). Studies on phytochemical and in-vitro antioxidant potential of Justicia beddomei (Clarke) Bennett. Free Radicals and Antioxidants, 2(4), 26-31.

McLellan, M.R., Lind, L.R. and Kime, R.W. (1994). Hue angle determination and statistical analysis for multiquadrant hunter L,a,b data. Journal of Food Quality, 18, 235-240.

Mosmann, T. (1983). Rapid colorimetric assay for cellular growth and survival: application to proliferation and cytotoxicity assays. Journal of Immunological Methods, 65, 55-63.

Ortez, J.H. (2005). Disk Diffusion Testing. In Coyle, M.B. (Ed.), Manual of Antimicrobial Susceptibility Testing, p. 39-52. USA: American Society for Microbiology.

Parvathy, K., Negi, P. and Srinivas, P. (2009). Antioxidant, antimutagenic and antibacterial activities of curcumin $\beta$-diglucoside. Food Chemistry, 115, 265-271.

Philippines, Department of Agriculture (Phil-DA). (2011). Pili Technoguide. Retrieved on September 24, 2014 from Phil-DA Website: http:// bicol.da.gov.ph/attachments/article/28/Pili\% 20Technoguide.pdf.

Rhee, J., Diaz Ricci, J., Bode, J. and Schugerl, K. (1994). Metabolic enhancement due to plasmid maintenance. Biotechnology Letters, 16, 881-884.

Serra, M., Trujillo, A.J., Guamis, B. and Ferragut, V. (2009). Evaluation of physical properties during storage of set and stirred yogurts made from ultrahigh pressure homogenization-treated milk. Food Hydrocolloids, 23, 82-91.

United States Food and Drug Administration (US FDA). (2001). Bacteriological Analytical Manual: Aerobic Plate Count ( $8^{\text {th }}$ ed.). Retrieved on September 24, 2014 from US FDA website: http://www.fda.gov/ Food/FoodScienceResearch/LaboratoryMethods/ ucm063346.htm.

Vijayarathna, S. and Sasidharan, S. (2012). Cytotoxicity of methanol extracts of Elaeis guineensis on MCF-7 and Vero cell lines. Asian Pacific Journal of Tropical Biomedicine, 2(10), 826-829.
Wallace, T.C. and Giusti, M.M. (2008). Determination of color, pigment, and phenolic stability in yogurt systems colored with nonacylated anthocyanins from Berberis boliviana L. as compared to other natural/ synthetic colorants. Journal of Food Science, 73(4), 241-248.

Wang, H., Cao, G. and Prior, R.L. (1997). The oxygen radical absorbing capacity of anthocyanins. Journal of Agriculture and Food Chemistry, 45, 304-309.

Wang, J. and Mazza, G. (2002). Inhibitory effects of anthocyanins and other phenolic compounds on nitric oxide production in LPS/IFN- $\gamma$-actived RAW 2647 macrophages. Journal of Agricultural and Food Chemistry 50, 850-857.

Wang, J., Shen, X. and Chen, Y. (2013). Effect of pH, temperature, and iron on the stability of anthocyanins from black-skinned peanuts (Arachis hypogaea L.). African Journal of Agricultural Research 8(18), 2044-2047.

Wang, L. and Stoner, G.D. (2008). Anthocyanins and their role in cancer prevention. Cancer Letters, 269, 281-290.

Yang, Z. and Zhai, W. (2010). Identification and antioxidant activity of anthocyanins extracted from the seed and cob of purple corn (Zea mays L.). Innovative Food Science and Emerging Technologies, 11, 169-176.

Zhang, Y., Vareed, S.K. and Nair, M.G. (2005). Human tumor cell growth inhibition by nontoxic anthocyanidins, the pigments in fruits and vegetables. Journal of Life Sciences, 76, 1465-1472.

Zheng, W. and Wang, S.Y. (2003). Oxygen radical absorbing capacity of phenolics in blueberries, cranberries, chokeberries and lingonberries. Journal of Agriculture and Food Chemistry, 51, 502-509. 